\title{
CARACTERIZACION DE LA PULPA DE Physalis peruviana L. CULTIVADA EN EL DEPARTAMENTO DE NORTE DE SANTANDER - COLOMBIA
}

Clemente Granados-Conde ${ }^{1 *}$, Miladys Torrenegra-Alarcón ${ }^{2}$, Candelaria Nahir Tejada-Tovar ${ }^{3}$.

1 Ingeniero de Alimentos. Magister en Ciencias y Tecnología de Alimentos, docente del programa de Ingeniería de Alimentos, Grupo de investigación Ingeniería, Innovación, Calidad Alimentaria y Salud (INCAS). Universidad de Cartagena, Cartagena, Colombia. Teléfono: (575)6699771 Celular: (57)3158332900. *Autor correspondiente

2 Ingeniera de Alimentos. Magister en Ciencias y Tecnología de Alimentos, Grupo de Investigación de Nano, Biotecnología e Innovación (GIBEI). ${ }^{2}$ Centro de Comercio y Servicios, Regional Bolívar (SENA), Cartagena, Colombia.

3 Ingeniera de Química. Magister en Ingeniería Ambiental, docente del programa de Ingeniería Química, Grupo de investigación en diseño de procesos y aprovechamiento de biomasas -IDAB- Universidad de Cartagena, Cartagena, Colombia. 


\section{RESUMEN}

La uchuva (Physalis peruviana L.), pertenece a la familia de las Solanáceas y al género Physalis, es una de las frutas con mayor contenido vitamínico, además posee minerales como calcio, fósforo y hierro. En Colombia se comercializa en fresco constituyéndose en toda una industria que representa ganancia para los fruticultores, al ser considerada como una de las frutas tropicales más gustosas y promisorias. Por lo tanto, se caracterizó la pulpa de Physalis peruviana L. cultivada en el municipio de Pamplona ubicado en el departamento de Norte de Santander Colombia. La uchuva (Physalis peruviana L.), fue recolectada en el municipio de Pamplona, ubicado en el departamento de Norte de Santander $\left(7^{\circ} 22^{\prime} 34^{\prime \prime} \mathrm{N}\right.$ $\left.72^{\circ} 38^{\prime} 54^{\prime \prime O}\right)$. La pulpa de la uchuva se obtuvo a partir del fruto; y le se determinó $\mathrm{pH}$, ${ }^{\circ}$ Brix, acidez titulable, índice de madurez, contenido de vitamina $\mathrm{C}$ (ácido ascórbico), humedad, ceniza, grasa, proteínas, fibra cruda, carbohidratos y minerales (Calcio, fosforo y hierro).

Los sólidos solubles totales $13,50^{\circ}$ Brix, acidez 1,90\% ácido cítrico, índice de maduración $7,10, \mathrm{pH} 3,62$, ceniza $0,89 \%$, humedad $82,07 \%$, proteína $1,25 \%$, grasa 0,35\%, fibra cruda $4,12 \%$, carbohidratos $15,44 \%$ y Vitamina C $35,79 \mathrm{mg}$ ácido ascórbico. El mineral más abundante presente en la pulpa de la uchuva es el fosforo con un valor de $35,5 \mathrm{mg}$.

La pulpa de la uchuva (Physalis peruviana L.), es considerada como promisorio para diseñar productos nutracéuticos por su elevado contenido de vitamina $\mathrm{C}$.

Palabras clave: Pulpa, vitamina C, Physalis peruviana L. 


\section{CHARACTERIZATION OF THE PULP OF Physalis peruviana L. CULTIVATED IN THE DEPARTMENT OF NORTH OF SANTANDER-COLOMBIA}

\section{ABSTRACT}

The Cape Gooseberry (Physalis peruviana L.) belongs to the Solanaceae family and the genus Physalis, it is one of the fruits with the highest vitamin content, also has minerals such as calcium, phosphorus and iron. In Colombia it is sold fresh becoming an entire industry that represents profit for growers, to be considered as one of the most tasty and promising tropical fruit. Therefore, characterized the pulp of Physalis peruviana L. grown in the municipality of Pamplona, located in the Department of Norte de Santander - Colombia. The Cape Gooseberry (Physalis peruviana L.), was collected in the municipality of Pamplona, located in the Department of Norte de Santander $\left(7^{\circ} 22^{\prime} 34^{\prime \prime N} 72^{\circ} 38^{\prime} 54^{\prime \prime} \mathrm{O}\right)$. The Cape Gooseberry fruit pulp was obtained from the fruit; and was determined $\mathrm{pH},{ }^{\circ}$ Brix, maturity index, titratable acidity, content of vitamin C (Ascorbic acid), moisture, ash, fat, protein, crude fiber, carbohydrates and minerals (calcium, phosphorus and iron).

The solid soluble total $13.50^{\circ}$ Brix, acidity $1.90 \%$ citric acid, index of maturation 7.10 , pH 3.62 , ash $0.89 \%$, humidity $82,07 \%$, protein $1.25 \%$, fat $0.35 \%$, crude fiber $4.12 \%$, carbohydrates $15.44 \%$ and vitamin C 35, 79mg Ascorbic acid. He ore more abundant present in the pulp of the Cape Gooseberry is the phosphorus with a value of 35, 5 mg.

The pulp of the Cape Gooseberry (Physalis peruviana L.), is considered as promising for nutraceutical products designed by its high content of vitamin $\mathrm{C}$. Key words: pulp, vitamin C, Physalis peruviana L. 


\section{INTRODUCCION}

Colombia es un país que se caracteriza por tener una posición geográfica privilegiada que lo hace potencialmente rico en fauna y flora ${ }^{1}$. Los cultivos se reconocen por producir exitosamente la mayoría de los alimentos de las tierras en las que se cultivan dichos productos, que cuentan con un nivel de fertilidad único e inigualable. Colombia presenta un clima favorable que permite que las regiones que lo conforman sean parte del crecimiento y del desarrollo rural del país, los productos son destacados como los de mejor calidad y diferenciación dentro de los que se cultivan a nivel mundial ${ }^{2}$.

La uchuva (Physalis peruviana L.), pertenece a la familia de las Solanáceas y al género Physalis, cuenta con más de 80 variedades que se encuentran en estado silvestre y que se caracterizan porque sus frutos están encerrados dentro de un cáliz o capacho ${ }^{3,4}$.

La uchuva, originaria de los Andes suramericanos, es un fruto autóctono de Colombia, es la especie más conocida de este género y se caracteriza por tener unos frutos azucarados y buenos contenidos de vitaminas $\mathrm{A}$ y $\mathrm{C}$, además de hierro, calcio y fósforo ${ }^{5}$. Colombia es a su vez el primer productor mundial de Uchuva, seguido igualmente por Sudáfrica, diferenciándose sus frutos por el tamaño, el color, el sabor, la forma del cáliz y el porte de la planta. Actualmente se cultivan tres tipos de uchuva, originarias de Colombia, Kenia y Sudáfrica ${ }^{6}$. La uchuva colombiana se caracteriza por tener mejor coloración y mayor contenido de azucares, características que la hacen apetecible en los mercados ${ }^{5-7}$. Las principales áreas cultivadas en Colombia se localizan en los departamentos de Cundinamarca, Boyacá y Antioquia atribuyéndosele asimismo propiedades medicinales ${ }^{8-10}$.

Por lo cual en este trabajo se caracterizó la pulpa de uchuva, cultivada en el departamento de Norte de Santander, Colombia.

\section{MATERIALES Y METODOS}

Se utilizaron uchuva (Physalis peruviana L.), adquiridas en un mercado local del municipio de Pamplona, Norte de Santander ( $\left.7^{\circ} 22^{\prime} 34^{\prime \prime} \mathrm{N} 72^{\circ} 38^{\prime} 54^{\prime \prime O}\right)$. 
Las uchuvas se seleccionaron teniendo en cuenta que estuvieran libres de daños externos y presentaran madurez comercial; se lavaron y escaldaron a $90^{\circ} \mathrm{C}$ por 5 minutos. Las pulpas se obtuvieron mediante refinadora de malla $1.5 \mathrm{~mm}$ de abertura; se empacaron en bolsas herméticas y posteriormente se refrigeraron a una temperatura de $4^{\circ} \mathrm{C}{ }^{11}$.

El contenido de humedad se determinó según el método AOAC 930.15/90; el pH según el método AOAC 981.12/90 con un potenciómetro por inmersión del electrodo en la muestra, previa calibración con soluciones tampón de $\mathrm{pH} 2,4,7$ y 10 a $25^{\circ} \mathrm{C}$; solidos solubles según método AOAC 932.12/90 con un refractómetro digital HANNA, USA; la acidez se determinó por el método AOAC 942.05/90 por titulación con $\mathrm{NaOH}$ y se expresó como g / $100 \mathrm{~g}$ de ácido cítrico y el índice de madurez se obtuvo de la relación entre los sólidos solubles totales y la acidez titulable ${ }^{6,11-13}$, contenido de vitamina C (ácido ascórbico) por el método de titulación yodometrica. Los contenidos de fibra cruda, cenizas, grasa, carbohidratos y proteína se determinaron según la metodología descrita Morillas y Delgado ${ }^{14}$.

\section{Determinación de minerales}

Las muestras secas y calcinadas (cenizas) fueron tratadas con $\mathrm{HCl}$ de acuerdo al método recomendado por la AOAC. Los minerales $\mathrm{P}, \mathrm{Ca}^{2+}$ y $\mathrm{Fe}^{2+}$ se determinaron por espectrofotometría de absorción atómica.

\section{Análisis Estadístico}

Los resultados correspondientes a tres ensayos independientes se expresaron como el promedio \pm el error estándar de la media (ESM). Para la organización de los datos se empleó la hoja de cálculo MS Excel 2010, y para los análisis estadísticos el paquete GraphPad Prism V5.00 para Windows.

\section{DISCUSION Y RESULTADOS}

La calidad de un fruto contempla además de sus características físicas -tamaño, peso, color y textura- su contenido nutricional, expresado en sólidos solubles totales, acidez y nutrientes. 
Tabla 1. Caracterización química de la pulpa de uchuva (Physalis peruviana L.), cultivada en el departamento de Norte de Santander - Colombia.

\begin{tabular}{|c|c|}
\hline Parámetros evaluados & Resultados \\
\hline $\mathrm{pH}$ & $3,62 \pm 0,5$ \\
\hline Acidez & $1,90 \pm 0,5$ \\
\hline $\begin{array}{c}\text { Solidos solubles totales } \\
\text { (SST) }\end{array}$ & $13,5 \pm 0,2$ \\
\hline $\begin{array}{c}\text { Índice de maduración } \\
\text { (SST/Acidez) }\end{array}$ & $7,10 \pm 0,8$ \\
\hline Densidad (g/mL) & $1,05 \pm 0,1$ \\
\hline Ceniza & $0,89 \pm 0,65 \%$ \\
\hline Humedad & $82,07 \pm 0,95 \%$ \\
\hline Proteína & $1,25 \pm 0,82 \%$ \\
\hline Grasas & $0,35 \pm 0,55 \%$ \\
\hline Fibra cruda & $4,12 \pm 0,35 \%$ \\
\hline Carbohidratos & $15,44 \pm 0,55 \%$ \\
\hline Vitamina C & $35,79 \pm 0,15 \%$ \\
\hline Calcio & $10,5 \pm 0,4 \mathrm{mg}$ \\
\hline Hierro & $1,1 \pm 0,5 \mathrm{mg}$ \\
\hline Fosforo & $35,5 \pm 0,15 \mathrm{mg}$ \\
\hline
\end{tabular}

En los resultados (Tabla 1) se puede observar que la pulpa de la uchuva evaluada tiene un alto contenido de humedad, habiendo obtenido un valor de $82,07 \pm 0,95 \%$. Las frutas contienen $0,1-1,5 \%$ de compuestos nitrogenados, de ellos las proteínas constituyen un $35-75 \%$ en las frutas; los aminoácidos también se encuentran bien representados. La fracción de los compuestos nitrogenados solubles está formada como promedio por un $50 \%$ de aminoácidos libres. Todos los demás compuestos nitrogenados son bastante escasos. También cabe resaltar que la mayor parte de la fracción proteica, la cual se encuentra sometida a grandes cambios dependientes de la clase de fruta y su grado de madurez, está constituida por enzimas. La cantidad de proteína en las frutas es baja ${ }^{14}$. 
Los resultados obtenidos en los análisis químicos realizados en la pulpa de uchuva son similares a los incluidos en los estudios realizados por Mendoza et a ${ }^{6}$ en donde caracterizaron las propiedades físico químicas de la uchuva (Physalis peruviana) obtenida en la región de Silvia-Cauca y Duque ${ }^{7}$ en el cual formuló y caracterizó productos solubles de uchuva (Physalis peruviana L.) para la producción de pulpa fortificada.

Los valores de acidez titulable de las muestras de uchuva son similares a los obtenidos por Mendoza et $\mathrm{al}^{6}$, no obstante, difieren de los resultados obtenidos por Márquez et al ${ }^{15}$, sin embargo, éstos indican que los frutos cultivados en la zona mantienen su grado de acidez en las diferentes épocas del año.

Los valores de $\mathrm{pH}$ de las pulpas se encuentran dentro del rango de la mayoría de las frutas tropicales $(2,6-5,8)^{16}$. Desde el punto de vista tecnológico, el pH en las frutas, es un parámetro muy importante en el control del desarrollo de poblaciones de microorganismos, responsable de la actividad de sistemas enzimáticos, en el proceso de clarificación de jugos y bebidas, en la estabilidad de los mismos y de otros productos elaborados a partir de frutas; así como en la producción de jalea y mermelada cuya firmeza, color y flavor están determinados por la concentración de iones hidrógenos ${ }^{14,16}$.

El contenido de carbohidratos totales es muy variable entre frutas y vegetales, encontrándose en frutas entre el 1 al $8 \%$. Así, en las frutas el contenido de azúcares aumenta con la maduración ${ }^{14}$.

Con respecto al contenido de lípidos, estos fueron muy bajos como en la mayoría de las frutas, comprendido principalmente por acilglicéridos, glicolípidos, fosfolípidos, carotenoides, triterpenoides y ceras ${ }^{14,16}$.

Los alimentos cuentan con diversos componentes dentro de los que se encuentran los minerales, algunos esenciales para el organismo, por esto es necesario conocer las cantidades que contienen los frutos de la uchuva. Se observó que la uchuva presento un alto contenido de minerales con un valor de cenizas de $0,89 \pm 0,65 \%$ probablemente pertenecientes a minerales como el fosforo, calcio y hierro. 
El orden de importancia de los minerales encontrados en la pulpa de uchuva fue el siguiente: Fósforo >Calcio > Hierro, los resultados obtenidos por cada mineral en particular se encuentran dentro del rango establecido por Erkaya et al. ${ }^{10}$ los cuales indican valores para fosforo $27-55,3 \mathrm{mg}$, calcio $2-28 \mathrm{mg}$ y hierro $0,3-1,2 \mathrm{mg}$ respectivamente.

\section{CONCLUSIONES}

La pulpa de uchuva (Physalis peruviana L.), es considerado como promisorio para diseñar productos nutracéuticos por su elevado contenido de vitamina $\mathrm{C}$.

\section{AGRADECIMIENTOS}

Los autores agradecen a la Universidad de Cartagena y al SENA por facilitar espacio, recursos y tiempo de los investigadores.

\section{BIBLIOGRAFÍA}

1. Torrenegra M, Granados C, Osorio M, León G. Method comparison of hydrodistillation microwave radiation-assisted (MWHD) front hydrodistillation (HD) in the extraction of essential oil of Minthostachys mollis. Inf Tecnol. 2015;26(1):117122.

2. Vásquez JA, Torres AL. El mercado de la uchuva en Colombia y sus proyecciones para la penetración y comercialización en el mercado de los Estados Unidos. [Tesis de pregrado]. Pereira (Colombia): Universidad Católica de Pereira, Facultad de Ciencias Económicas y Administrativas, 2012.

3. Cortés M, Herrera EA, Gil JH. Impregnación de uchuva (Physalis peruviana L.) de forma semiesférica con una emulsión fortificante. Biotecnología en el Sector Agropecuario y Agroindustrial. 2016; 14(1):27 - 36

4. Peña $P$, Cortés $M$, Gil JH. Uchuva mínimamente procesada impregnada al vacío con calcio y vitaminas B9, D y E. Biotecnología en el sector Agropecuario y Agroindustrial, 13(1), 2015: 110-119. 
5. Duque AL, Giraldo GA, Cortés M. Desarrollo de una pulpa funcional de uchuva adicionada de calcio, vitamina C Y fibra dietaría. Vitae. 2012; 19(1):180-182

6. Mendoza JH, Rodríguez A, Millán P. Caracterización físico química de la uchuva (Physalis peruviana) en la región de Silvia Cauca. Biotecnología en el Sector Agropecuario y Agroindustrial. 2012; 10(2):188 - 196.

7. Duque A. Formulación y caracterización de productos solubles de uchuva (Physalis peruviana L.) para la producción de pulpa fortificada [Tesis de maestría]. Armenia (Colombia): Universidad del Quindío, Facultad de Ciencias Básicas y Tecnologías, 2011.

8. Fischer G, Almanza-Merchán PJ, Miranda D. Importância e cultivo do (Physalis peruviana L.) no mundo. Rev. Bras. Frutic., Jaboticabal - SP. 2014; 36(1): 1-15. 9. Duque AL, Giraldo GA, Cortés M. Fortificación de pulpa de uchuva con calcio, oligofructosa y vitamina C, estabilizada con hidrocoloide. Biotecnología en el Sector Agropecuario y Agroindustrial. 2014; 12(1): 124-133.

10. Erkaya T, Dağdemir E, Şengül M. Influence of Cape gooseberry (Physalis peruviana L.) addition on the chemical and sensory characteristics and mineral concentrations of ice cream. Food Research International. 2012; 45(1), 331-335.

11. Morón FJ, Déborah P, Nodarse M. Valoración de la evidencia científica para recomendar Annona muricata L. (guanábana) como tratamiento o prevención del cáncer. Revista Cubana de Plantas Medicinales.2010; 15(3): 169-181.

12. AOAC. Fruits and fruits products. In K. Helrich (ED) Official methods of Analysis of the Association of Official Analytical Chemists. Arlington, 1990 USA: AOAC 13. Norma técnica colombiana NTC 4580 de 1999. Caracterización grados de madurez de la uchuva.

14. Morillas-Ruiz JM, Delgado-Alarcón JM. Análisis nutricional de alimentos vegetales con diferentes orígenes: Evaluación de capacidad antioxidante y compuestos fenólicos totales. Nutr. clín. diet. hosp. 2012; 32(2):8-20.

15. Márquez CJ, Trillos $O$, Cartagena JR, Cotes JM. Evaluación físicoquímica y sensorial de frutos de uchuva (Physalis peruviana L.). Vitae. 2009; 16(1), 42 - 48. 
16. Ramírez R, Arenas L, Acosta K, Yamarte M, Sandoval L. Efecto del escaldado sobre la calidad nutricional de pulpa de Guanábana (Annona muricata L.). Revista Iberoamericana de Tecnología Postcosecha, 2012; 13(1): 48-57. 